\title{
Attitudes and behaviors towards mental illness of pre-service teachers in educational sciences
}

\section{Ioana DARJAN, Anca LUȘTREA•}

\begin{abstract}
The personal system of beliefs and attitudes influence emotional and behavioral reactions. In educational field, teachers' systems of beliefs, their set minds are of extreme importance, as they will direct and impact on their classroom practices, relational and instructional approaches. The pre-service teachers in Educational Sciences will become qualified professionals in educational field, in all its forms: mainstream, special, and integrated education. The future teachers face an extremely fluid educational environment, in terms of students' characteristics, educational objectives, both academic and social, instructional and formative needs. With an increasing rate of school inclusion of students with Special Educational Needs (SEN) (Horga, 2016), the future specialists should be prepared, in terms of competences, to promote and sustain inclusion, to act against discrimination and exclusion, to advocate for the rights of all their students. Aiming to prepare highly qualified education specialists, it is important to assess their attitudes and positions towards students with diverse special needs, from diverse special contexts. As future specialists in education, our pre-service teachers will work directly with students with special needs and their families and will represent important agents in changing mentalities and generating adequate attitudinal and behavioral changes. In this study, we investigate our pre-service teachers' the knowledge, attitudes and behaviors towards mental illness. A survey questionnaire covering topics as knowledge, attitudes and behavior towards people with mental illness was administrated to 82 of our pre-service teachers. The study presents the findings and the conclusions of the survey.
\end{abstract}

Key words: mental illness;pre-service teachers; attitudes.

\section{Introduction}

Mental illness is a very controversial and complex topic for the public agenda. The importance of this condition derived from the fact that it impacts not only on individual level,

\footnotetext{
- Lecturer PhD, West University of Timisoara, Romania, , University Clinic for Therapies and Psychopedagogic Counselling, ioana.darjan@e-uvt.ro

- Associate professor, Phd., West University of Timisoara, Romania, , University Clinic for Therapies and Psycho-pedagogic Counselling, anca.lustrea@e-uvt.ro
} 
but affects the entire family, community and society. At individual level, mental illness could affect autonomy, functionality, productivity, relationships, inclusion, and wellbeing of afflicted people. At community and society levels, mental illness might be perceived as important factor for disfunctions, crises, conflicts, damages and budget-consuming, for restoration/repairs and treatments. Furthermore, mental illness is still an important motif for discrimination and stigma.

The relation between knowledge and attitude towards mental illness at college students was researched before (Pascucci et.al, 2017). Good knowledge about mental health seems to be associated with better attitudes towards people afflicted by it.

Personal experience with mental illness, such as having someone with this condition in the close proximity, in the family, close social circle or at work, have also impact in attitudinal and behavioral responses (Waugh, Lethem, Sherring Henderson, 2017; Sottie, MfoafoM'Carthy, Moasun, 2018). People tend to have a better attitude towards mental illness if they have close relations with people with mental illness and tend to change their attitudes if mental illness intervenes in their family life.

Beliefs about and attitudes towards mental illness impact on discrimination and stigmatizing actions. Feeg, Prager, Moylan, Smith and Cullinan (2014) find in a population of college students that those who are less familiar with mental illness tend to maintain the social distance and stigmatize more. Our study tried to investigate the relations between attitudes and predisposition for discriminating and stigmatizing people with mental illness.

Mental illness in children and adolescence is a more controversial topic, as it is a developmental pathology, depending of many factors, hereditary and environmental.

The life-trajectory of affected children could be altered by the adopted measures.

The main agencies for socialization and enculturation are families and schools.

Schools are witnessing some extreme effects of under-diagnosticated, unaddressed, untreated mental illness: conflicts, hetero and self-aggressive behaviors, suicidal ideations, attempts and acts.

There are serious issues that solicit and support the necessity and opportunities for schools and their agents to assume and stress their formative and therapeutic roles, alongside the instructional ones (Dârjan et al., 2015, Dârjan, 2018).

The most demanding issues are: 
- The increasing number of children with visible and invisible emotional and behavioral disorders (EBD), whom problems are not address appropriately in school (Forness, Freeman, Paparella, Kauffman, Walker, 2012; Kauffman, Mock, Simpson, 2007, as cited by Losinski et al., 2015);

- Insufficient preoccupation during initial teachers' training in developing teachers' competencies for approaching and working with challenging students;

- Irrational beliefs and unrealistic expectations, based on prejudice, discrimination, which encourage stigma, rejection and isolation of the children with problematic behaviors.

Teachers and all the educational professionals are called to broaden their roles, contributing to the early identification, referral and intervention for the children who experience mental illness or are in risk (Forness, 2003, Maag Katsiyannis, 2010, as cited by Losinski et al., 2015).

Furthermore, teachers are role models, they contribute to the building of system of beliefs, values and moral principles, they have the power to change mentalities. Their systems of beliefs and attitudes will impact the students' systems of beliefs and attitudes, which are shaped throughout childhood and adolescence (Beck, J., 2011; Byrne, 2000). Thus, teachers' positive attitudes towards mental illness, knowledge about it, without misinformation and prejudice, have the potential to reduce stigma and discrimination toward people with mental illness in society. Although teachers tend to adopt negative attitudes toward mental illness (Gur et al., 2012), a sounding solution, with long-term impact, is to educate them during initial training so they could develop a more positive framework for the people with mental illness.

Many studies ((Vibha, Saddichha, and Kumar, 2008; Caldwell \& Jorm, 2000; Nordt, Rossler, \& Lauber, 2006) demonstrate that attitudes and behaviors towards mental illness improve with better knowledge and understanding of this phenomenon, with previous, more experiences with people who had mental illness, greater educational level. 


\section{Method}

\section{Research question}

Universities could meet these needs for relevant and sounding knowledge about mental illness, and to develop positive attitudes toward mental illness for the pre-service teachers enrolled in academic programs.

Based on the above arguments the following research question was advanced:

Which individual factors influence the attitudes towards mental illness?

From the multitude of individual factors that can influence the formation of attitudes we have considered the ones that, in our opinion, can have a high impact: the knowledge about mental illness, personal experiences and with mental illness, attitudes towards intervention, openness/willingness to relate with persons with mental illness and the perception of stigma.

\section{Methodology}

This study was designed to determine the pre-service teachers' knowledge and attitudes toward mental illness, and to identify possible individual factors that affect them. 82 pre-service teachers from Special Education and Pedagogy specializations of our Educational Sciences Department answered a questionnaire and a demographic survey.

\section{Research hypotheses}

1. The pre-service teachers' attitudes towards mental illness correlate with their knowledge in the field.

2. There will be a correlation between pre-service teachers' attitudes towards mental illness and personal experience with the condition.

3. There will be a correlation between pre-service teachers' attitudes towards mental illness and attitudes towards intervention.

4. There will be a correlation between pre-service teachers' attitudes towards mental illness and their willingness to be around people with mental illness conditions.

5. There will be a correlation between pre-service teachers' attitudes towards mental illness and the perceived stigma.

6. There will be a difference in pre-service teachers' attitudes towards mental illness from families with or without a member with mental illness.

\section{Participants and procedure}


Data were collected from a convenience sample of 82 pre-service teachers from Special Education and Pedagogy specializations. The age of participants ranged from 18 to 51 years $(M=23.40, S D=8.31)$. Participants were $3(3.7 \%)$ men and 79 (96.3\%) women. The preservice teachers were from 2 specializations, 42 (51.2\%) in Special Education and 40 (48.8\%) in Pedagogy. The pre-service teachers from all three study years were included: 24 (29.3\%) were from the first year of studies, 35 (42.7\%) from the second and 23 (28\%) from the third.

\section{Research instrument}

This study used asurvey questionnaire. It wasadapted from the instrument used to assess the attitudes to mental illness of adult from England, since 1994 (Attitudes to Mental Illness, 2015). This instrument assesses the knowledge about mental illness, personal experiences of mental illness, and openness and willingness to live or interact with people with mental illness. The questionnaire collected also some demographic data (age, gender, specialization, year of study).

A consent letter, presenting the aims and the conditions of the study, was administered to all the pre-service teachers. From a total of 181 pre-service teachers, 82 filled-out the questionnaire.

\section{Results}

To determine the potential correlation between the pre-service teachers' attitudes towards mental illness and knowledge, personal experience, attitudes towards intervention, openness/willingness to be around people with mental illness and perceived stigma, the Pearson Correlations was computed (Table 1). Significant correlations were found between attitudes towards mental illness and personal experience $r(82)=.23, p=.03$, attitudes towards intervention $r(82)=.24, p=.02$ and openness/willingness $r(82)=.36, p=.00$. However, the effect size, $\mathrm{r}^{2}=0.05$ for personal experience and attitudes towards intervention, and $r^{2}=0.12$ for openness, indicates a relatively poor coefficient of determinationbetween personal experiences and attitudes towards intervention and attitudes towards mental illness. They explain only 5.29\% of attitudes variance. Also, openness/willingness explains only $12.96 \%$ of attitudes towards mental illness variance. 
Table 1: Correlations between attitudes towards mental illness and individual characteristics

\begin{tabular}{|c|c|c|c|c|c|c|}
\hline & 1 & 2 & 3 & 4 & 5 & 6 \\
\hline 1.Attitudes towards mental illness & - & .02 & $.23^{*}$ & $.24^{*}$ & $.36^{* *}$ & .07 \\
\hline 2. Knowledge & & - & .11 & $.23^{*}$ & -.05 & $.22^{*}$ \\
\hline 3. Personal experience & & & - & -.03 & $.22^{*}$ & .18 \\
\hline 4.Attitudes towards intervention & & & & - & .02 & .01 \\
\hline 5.Openness & & & & & - & .05 \\
\hline 6.Stigma & & & & & & - \\
\hline
\end{tabular}

*. Correlation is significant at the 0.05 level (2-tailed).

**. Correlation is significant at the 0.01 level (2-tailed).

As mentioned above, the pre-service teachers are enrolled in two different program study: Special Education and Pedagogy. Normally, Special Education curricula exposes students to more disciplines who offers knowledge about groups with special needs, who promote inclusion, and advocate against discrimination. Thus, we consider relevant to determine if there are differences between the two groups, in terms of attitudes and personal characteristics. For this purpose, an independent sample t-test was conducted (Table 2). Given a violation of Levene's test for homogeneity of variances, $F(1,80)=.39, p=.53$, a t-test not assuming homogeneous variances was calculated. The results of this test indicated that there was no significant difference in attitudes towards mental illness observed between the two groups, $t(79.98)=1.58, p=.11$. These results suggest that there is not a significant difference between Special Education group $(M=3.81 ; S D=.41)$ and Pedagogy group $(M=$ 3.67; $S D=.39$ ), in terms of attitudes towards mental illness.

Subsequently, no significant differences were obtained for most of the other individual characteristics.

Yet, in terms of openness/willingness to interact with people with mental illness, there is a clear difference between the two groups. The Special Education pre-service teachers have a significant more opened attitude towards people with mental illness and willingness to interact with them (Table 2). An independent sample t-test was conducted. Given a violation of Levene's test for homogeneity of variances, $F(1,80)=.34, p=.55$, a t-test not assuming homogeneous variances was calculated. The results of this test indicate that there was a significant difference in openness towards mental illness observed between the two groups, $t(77.06)=2.98, p=.00$. These results suggest that there is a significant difference between openness in Special Education group $(M=3.60 ; S D=.77)$ and Pedagogy group $(M=$ $3.05 ; S D=.89$ ). 
Table 2: Independent t-test Results Between Special Education and Pedagogy Pre-service teachers

\begin{tabular}{llllll}
\hline & \multicolumn{4}{l}{ Special Education } & Pedagogy \\
\hline & $M$ & $S D$ & $M$ & $S D$ & $t$-test \\
Attitudes towards mental illness & 3.81 & .41 & 3.67 & .39 & 1.58 \\
Knowledge & 3.87 & .69 & 3.76 & .85 & .67 \\
Personal experience & 1.63 & .58 & 1.60 & .58 & .23 \\
Attitudes towards intervention & 3.46 & .36 & 3.67 & .64 & -1.83 \\
Openness & 3.60 & .77 & 3.05 & .89 & 2.98 \\
Stigma & 2.42 & .47 & 2.43 & .49 & -.08 \\
\hline
\end{tabular}

Also, another potentialinfluence on type of attitudes is accumulated experience and exposure to the topic of mental illness, both theoretical, through acquired knowledge, and practical, through interventions. So, we compare the results from different study years. A one-way analysis of variance was conducted to determine if the attitudes towards mental illness differ between study years $(\mathrm{N}=82)$. The independent variable, study year, included three groups: first year of studies $(M=3.69, S D=.38, N=24)$, second year of studies $(M=3.80$, $S D=.41, N=35)$, and third year of studies $(M=3.71, S D=.42, N=23)$. For attitudes towards mental illness the assumption of normality was evaluated using histograms and found tenable for all groups. The assumption for homogeneity of variances was tested and found tenable using Levene`s test $F(2,79)=.71, p=.49$. The ANOVA was non-significant for all three groups (Table 4).

Table 3: One-way analysis of variance of attitudes towards mental illness by study year

\begin{tabular}{llllll}
\hline Source & $D f$ & $S S$ & $M S$ & $F$ & $P$ \\
\hline Between Groups & 2 & .238 & .119 & .711 & .494 \\
Within Groups & 79 & 13.233 & .168 & & \\
Total & 81 & 13.471 & & & \\
\hline
\end{tabular}

Table 4: ANOVA Comparisons of Attitudes Towards Mental Illness by Study year

\begin{tabular}{lllllll}
\hline & & & & \multicolumn{2}{l}{$\begin{array}{l}\text { Tukey's } \\
\text { Comparisons }\end{array}$} & HSD \\
\cline { 5 - 7 } Group & & $n$ & Mean & $S D$ & 1 & 2 \\
\hline 1. & First year & 24 & 3.69 & .38 & & \\
2. & Second year & 35 & 3.80 & .41 & \\
3. & Third year & 23 & 3.71 & .42 & \\
\hline
\end{tabular}


To determine if there is a difference in pre-service teachers' attitudes towards mental illness from families with or without a member with mental illness, an independent sample t-test was conducted (Table 5). Given a violation of Levene's test for homogeneity of variances, $F(1,80)=.13, p=.29$, a t-test not assuming homogeneous variances was calculated. The results of this test indicated that there was no significant difference in attitudes towards mental illness observed between the two groups, $t(11.18)=-1.16, p=.27$.

Table 5: Independent t-test Results Between Pre-service teachers without and with a family member with mental illness

\begin{tabular}{llllll}
\hline & \multicolumn{2}{l}{$\begin{array}{l}\text { Pre-service teachers } \\
\text { without a family member } \\
\text { with mental illness }\end{array}$} & $\begin{array}{l}\text { Pre-service teachers with } \\
\text { a family member } \\
\text { mental illness }\end{array}$ & \\
& $M$ & $S D$ & $M$ & $S D$ & t-test \\
Attitudes towards mental illness & 3.72 & .39 & 3.90 & .45 & -1.16 \\
\hline
\end{tabular}

These results suggest that there is not a significant difference between attitudes towards mental illness in pre-service teachers without a family member with mental illness group $(M=3.79 ; S D=.39)$ and pre-service teachers with a family member with mental illness group $(M=3.90 ; S D=.45)$.

\section{Conclusions}

In the context of a growing need of highly qualified teachers in the field of educational mental health we aimed to investigate pre-service teachers`attitudes about mental health and the individual factors that affect it

We designed a quantitative methodology, in which 82 pre-service teachers in Special Education and Pedagogy specializations responded to a questionnaire and a demographic survey.

In the research hypothesis we presume that will be a correlation between pre-service teachers' attitudes towards mental illness and the following individual factors: knowledge about the condition, personal experience with mental illness, attitudes towards intervention, openness to having a relation with people with mental illness and perception of stigma.

Significant correlations were found between attitudes towards mental illness and personal experience, attitudes towards intervention and openness. However, the effect sizes indicate a relatively poor coefficient of determination between these factors, explaining only $5.29 \%$ of attitudes variance for personal experience and attitudes towards intervention and 
$12.96 \%$ for openness. The most influential factor proves to be willingness for relations with people with mental illness.

Even though there were no many significant differences between Special Education and Pedagogy pre-service teachers in terms of attitudes towards people with mental illness, it is important to stress the one significant difference obtained: the openness and willingness to work, live and interact with persons with mental illness. The pre-service teachers in Special Education are more opened and willing to have relations with people with mental illness. The possible explanations reside in the specific of their theoretical and practical training. Relevant and scientific proven knowledge, practical intervention sessions, direct contact with people with special needs tend to improve perceptions and attitudes, diminish misinformation and prejudice, discrimination and stigma. This finding sustains the importance of initial formal training in improving attitudes and behaviors towards special groups (Maag et al., 2014; Predescu et al., 2017).

No significant differences were obtained between attitudes towards mental illness between pre-service teachers from the three study years, the level of studies is not a differentiating factor in terms of attitudes towards mental illness.

Also, we want to evaluate if there is a significant difference in attitudes towards mental illness between pre-service teachers who have a family member with mental illness and those who do not. No significant difference was obtained.

Universities have the responsibility to prepare highly specialized teachers, with adequate attitudes and reactions, prepared to respond efficiently to the broad range of challenges and demands pose by this profession.

Teachers are relevant agents in modelling behaviors and changing mentalities. Teachers could become key-resources in early identification and in educational and therapeutic intervention for students with mental illness. For these purposes, teachers' initial trainings should invest more in increasing teachers' awareness regarding mental illness, improving their knowledge and skills in working with children and adolescents in risk, and promoting positive attitudes towards special groups. 


\section{Limitations of the study and further research directions}

The main limitation of this research is the number of individual factors taken into consideration. From our findings, the best explanation for attitudes towards mental illness with only $12.96 \%$ of the variance explained is the openness/willingness towards relations with people with mental illness. Another limitation of the study is the relatively small number of participants; an increase of the responding pre-service teachers being desirable and essential for more relevant and generalized conclusions.

\section{Authorship statement}

The authors of this paper take public responsibility for the content and have had equal contribution in concept development, design, analysis, writing, or revision of the manuscript.

\section{References:}

*** Attitudes to Mental Illness. (2015). 2014 Research Report. Prepared to Change, file://C:/Users/Lenovo\%20V310\%20PC1/Documents/mental\%20illness/Attitudes to mental_illnes s 2014 report final 0.pdf

Beck, J. S. (2011). Cognitive Behavior Therapy. Basics and beyond. New York: The Guilford Press

Caldwell, T.M.; Jorm, A.F. (2000). Mental health nurses' beliefs about interventions for schizophrenia and depression: A comparison with psychiatrists and the public. Australian \& New Zealand Journal of Psychiatry, 34, 602-611.

Byrne, P. (2000). Stigma of mental illness and ways of diminishing it. Advances in Psychiatric Treatment, 6, 6572.

Dârjan, I. (2018). Modele de intervenţie la nivelul școlii pentru elevi în risc. Timișoara: Editura Universității de Vest

Darjan, I. (2017) Therapeutic community networks for children and youth at risk, Saarbrücken: Edition universitaires europeennes

Dârjan, I.; Luștrea, A.; Predescu, M. (2016) Rolul școlii în promovarea rezilienței copiilor cu dificultăți de învățare, în Crașovan, M. (coord) (2016) Educatie-evaluare-integrare, Timisoara, Ed. Universității de Vest

Feeg, V. D., Prager, L. S., Moylan, L. B., Smith, K. M., Cullinan, M. (2014). Predictors of Mental Illness Stigma and Attitudes among College Students: Using Vignettes from a Campus Common Reading Program. Issues in Mental Health Nursing, 35(9), 694-703. doi:10.3109/01612840.2014.892551

Gur, K.; Sener, N.; Kucuk, L.; Cetindag, Z.; Basar, M. (2012). The beliefs of teachers toward mental illness, Procedia - Social and Behavioral Sciences 47 ( 2012 ) 1146 - 1152

Horga, I. (2016). Educație pentru toţi ş̧ pentru fiecare : accesul şi participarea la educaţie a copiilor cu dizabilităţi şi/sau CES din școlile participante la Campania UNICEF Hai la şcoală! Alpha MDN. Retrieved from http://www.unicef.ro/wp-content/uploads/Educatia-pentru-toti-si-pentru-fiecare 2015.pdf

Losinski, M.; Maag, J.W.; Katsiyannis, A. (2015). Characteristics and Attitudes of Pre-Service Teachers toward Individuals with Mental Illness, Journal of Education and Practice, 6(3)

Maag, J.W.; Losinski, M.; Katsiyannis, A. (2014). Improving Pre-Service Teachers' Attitudes towards Individuals with Mental Illness through an Introduction to Special Education Course, International Education Research, 2(1), 33-43 
Nordt, C., Rossler, W.; Lauber, C. (2006) Attitudes of mental health professionals toward people with schizophrenia and major depression. Schizophrenia Bulletin, 32(4), 709-714.

Pascucci, M., Ventriglio, A., Stella, E., Di Sabatino, D., La Montagna, M., Nicastro, R., Bellomo, A. (2017). Empathy and attitudes towards mental illness among Italian medical students. International Journal of Culture and Mental Health, 10(2), 174-184. doi:10.1080/17542863.2016.1276947

Predescu, M.; Dârjan, I. (2017) A follow-up study of implementation of a positive approach to discipline ata school and classroom levels, in Journal of Educational Sciences, VIII no. 1 (35) 2017, 95-105

Sottie, C.A., Mfoafo-M'Carthy, M., Moasun, F. (2018). Graduate social work students' perceptions and attitude toward mental illness: implications for practice in developing countries, Social Work in Mental Health, 116. DOI: $10.1080 / 15332985.2018 .1448325$

Vibha, P.; Saddichha, S.; Kumar, R. (2008). Attitudes of ward attendants towards mental illness: Comparisons and predictors. International Journal of Social Psychiatry, 54, 469-478.

Waugh, V., Lethem, C., Sherring S., Henderson, C. (2017). Exploring experiences of and attitudes towards mental illness and disclosure amongst health care professionals: a qualitative study, Journal of Mental Health, 17. DOI: $10.1080 / 09638237.2017 .1322184$ 